\title{
Analysis of Thermal Comfort Conditions and Actual Energy Efficiency for Different Heating Systems in Test Buildings
}

\author{
Stanislavs Gendelis ${ }^{1}$, Andris Jakovičs ${ }^{2}$, Toms Dzenis ${ }^{3}$, Liene Bandeniece ${ }^{4}$ \\ ${ }^{1-4}$ University of Latvia
}

\begin{abstract}
The aim of this study is detailed analysis of longterm monitoring data on thermal comfort conditions and energy efficiency in small test buildings equipped with different heating systems. Calculations of PPD index and local thermal discomfort factors, as well as actual energy efficiency ratios for different heat pump systems are provided for the test buildings during three weeks of the heating season. It is shown that the type of heating system has an influence not only on heating energy needs, but also on thermal comfort conditions in the room.
\end{abstract}

Keywords - Test buildings, thermal comfort, PPD, heating systems, energy efficiency.

\section{INTRODUCTION}

Five experimental test buildings with internal dimensions $3 \times 3 \times 3 \mathrm{~m}$ have been built in Riga, Latvia (Fig. 1). They have identical building constructions (floor, ceiling, door, and window), but different outer walls for which mainly regional building materials are used, the buildings are named after the main outer wall material - AER, CER, EXP, LOG, PLY (see more in [1]). It is important to note that material thicknesses for the walls are chosen in such a way as to get the same calculated thermal resistance ( $U$-value) for all building structures. After first 2 years of project running huge amount of data has been collected and results (mainly about energy consumption for heating/cooling and humidity monitoring/modelling) have been published [1-5]. The analysed energy consumption for different buildings shows the differences between the calculated and measured heating energy, and it is taken into account for the calculation of actual energy efficiency of different heating systems.

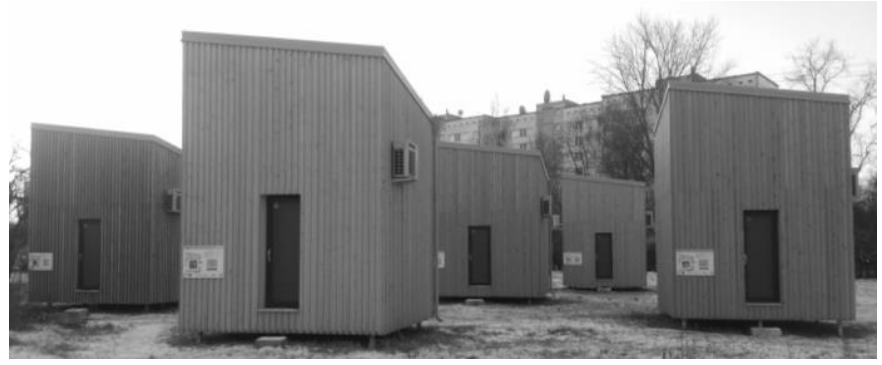

Fig. 1. Test buildings.
In the initial period, the buildings were equipped with identical air-air heat pumps, but in year 2014 the buildings were additionally equipped with different heating and cooling systems to perform detailed analysis of energy efficiency, their potential impact on temperature distribution and thereby also the thermal comfort conditions in a room. As heating season is still ongoing on the publication date, indicators of heat pumps' energy efficiency are only approximate. However, three week data of indoor thermal conditions is enough to analyse the differences in thermal comfort conditions (PMV and PPD indices, see [6]) depending on local discomfort factors (vertical temperature difference and draught rate) for heating system under real operating conditions.

\section{II.EXPERIMENTAL SET-UP}

Three new types of different heating systems were installed in the test buildings before year 2014 heating season, replacing the existing ones. As a result, four types of heating systems (Fig. 2) are running and monitored in the long term:

- a standard electric heater placed near the window, which is used as a reference (type EL, installed in building CER);

- an air-air heat pump (type A-A, installed in buildings AER and LOG);

- an air-water heat pump with water storage tank and lowtemperature large-sized convectors placed on the floor near outer wall (type A-W.F, installed in building PLY);

- an air-water heat pump with water storage tank and heating capillary mats placed on the ceiling (type AW.C, installed in building EXP).

Electric/heating power and integral energy consumption for heating systems, temperatures and humidity in the room at different heights, as well as outside air parameters (temperature, humidity, solar irradiation, etc.) are measured every minute during long-term monitoring. Location of main temperature/humidity sensors is shown in Fig. 3. In addition to fixed placement sensors, mean radiant temperature is periodically evaluated using portable microclimate measuring device DeltaOHM HD 32.1 (Fig. 4). 

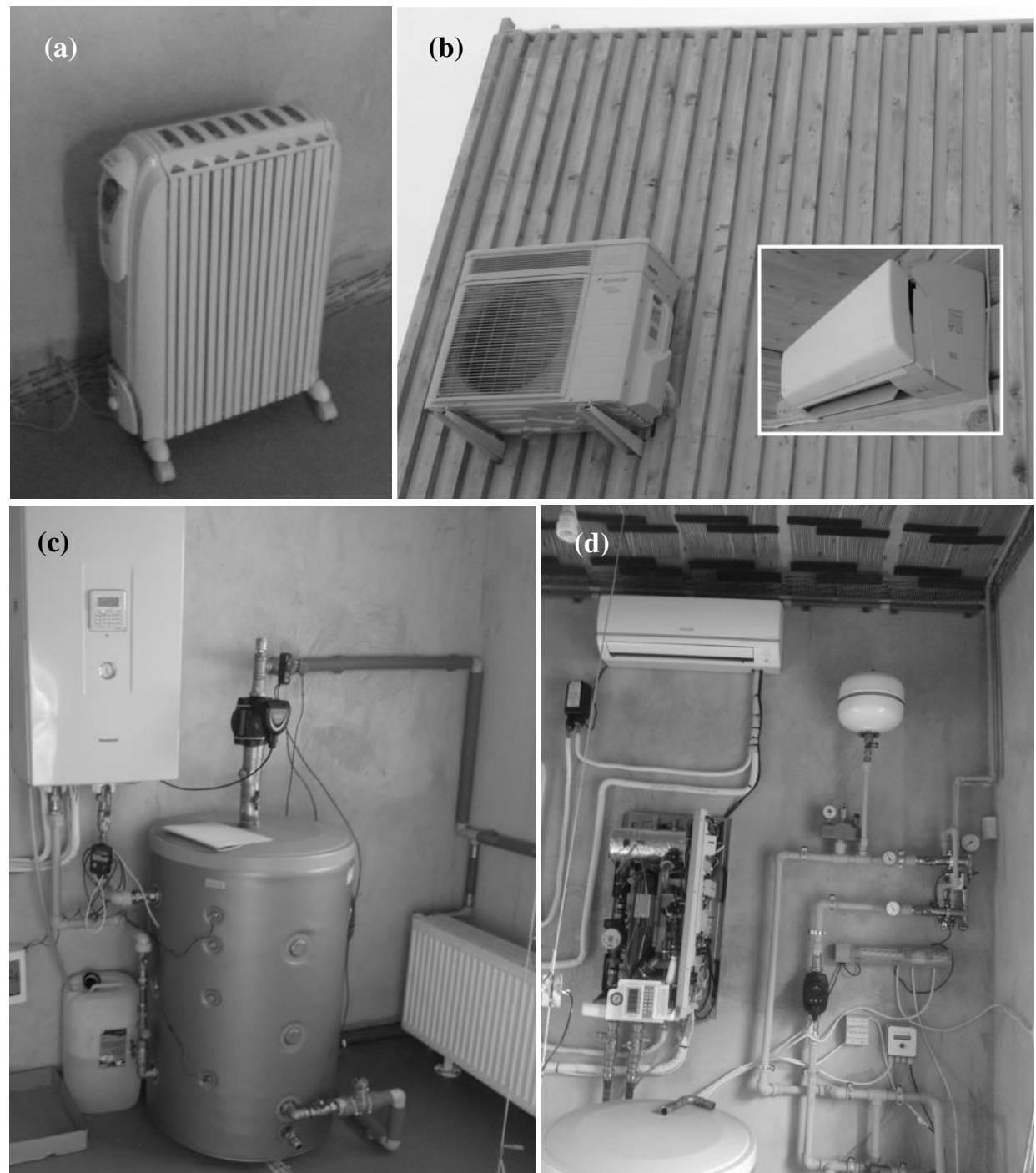

Fig. 2. Different heating systems investigated: (a) electric heater, (b) air-air heat pump, (c) air-water heat pump with convectors, (d) air-water heat pump with capillary mats placed on the ceiling.

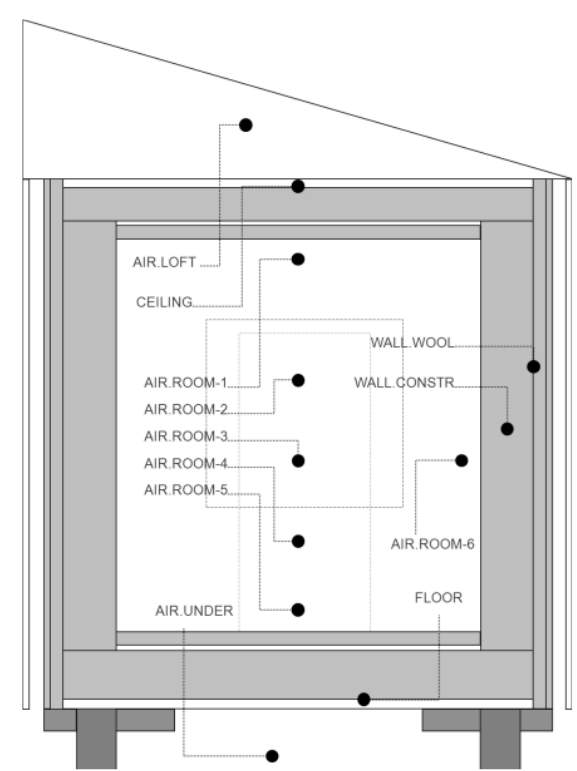

Fig. 3. Location of the main temperature sensors in a test building.

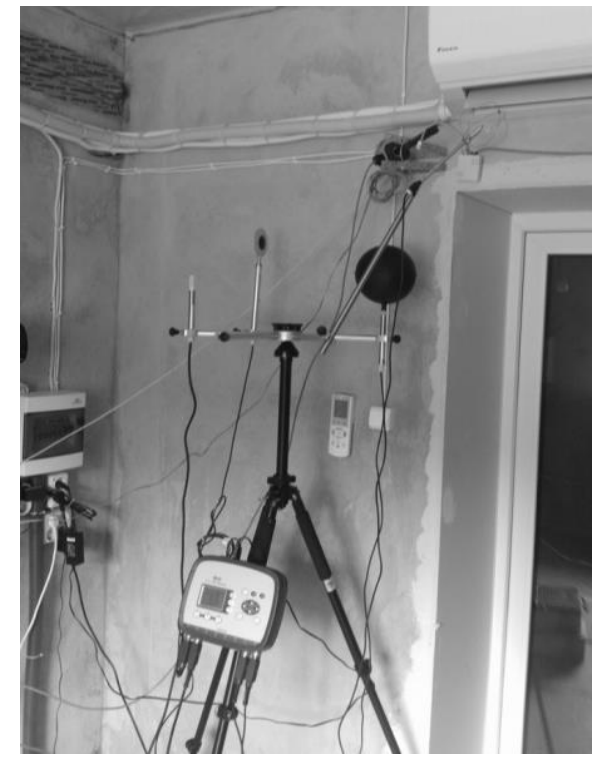

Fig. 4. Microclimate measuring device DeltaOHM HD 32.1. 


\section{METHODS}

\section{A. Thermal comfort parameters}

The type of heating system, the placement of a heater (heat exchanger) and corresponding different air movement regimes influence the temperature distribution (stratification) in the room, which is connected with the thermal comfort conditions in a room and local discomfort indicators.

The method described in LVS EN ISO 7730 standard [6] (hereinafter ISO 7730) is based on the determination of the predicted mean vote index (hereinafter PMV) calculated from an equation of thermal balance for the human body. The value of this index is calculated by taking into account internal heat production in the body and loss of the heat to the environment. Four measured environmental parameters - air temperature, mean radiant temperature, air velocity and air relative humidity, as well as two estimated factors - human metabolic rate (met) and clothing insulation (clo) are needed to calculate the PMV. The last 2 parameters generally are unknown, but we will use for further calculations the values according to sedentary activities $($ met $=1,2)$ during heating season $($ clo $=1)$ [6].

The other index proposed in ISO 7730 is the predicted percentage of dissatisfied people (hereinafter PPD) that quantifies the expected percentage of dissatisfied people in a given thermal environment. The variation of PPD index depending on PMV can be approximated by an expression that corresponds to a curve shown in Fig. 5 [6].

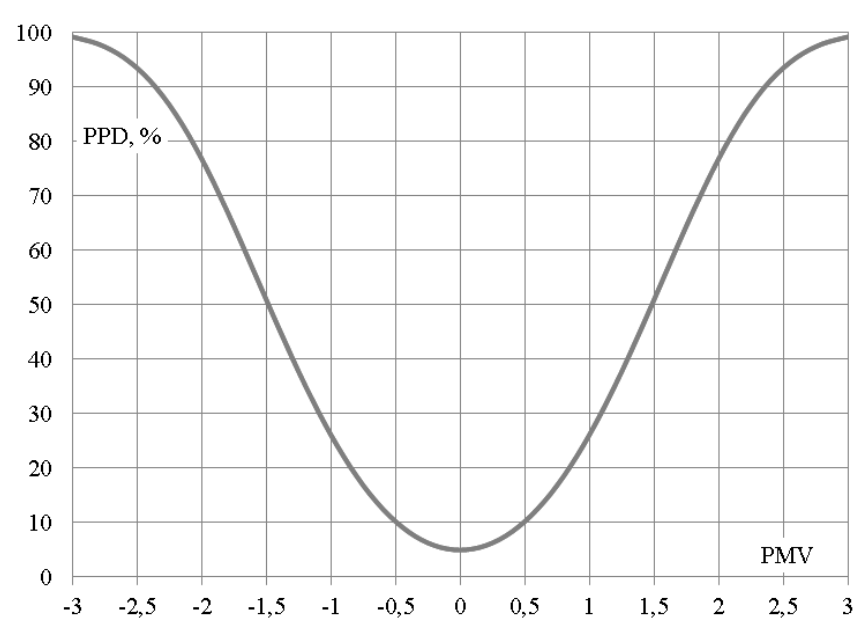

Fig. 5. Relationship between PMV and PPD indices [6].

According to ISO 7730, the desired thermal environment for a space may be selected from among 3 categories - A, B and $\mathrm{C}$ (Table 1). Each category prescribes a maximum percentage of dissatisfied people (PPD) for the body as a whole and local percentage dissatisfied (PD) for local discomfort. PPD index and two of local discomfort parameters - draught rate (DR) and PD caused by vertical temperature difference between head $(1.1 \mathrm{~m})$ and ankles $(0.1 \mathrm{~m})$ for sitting person will be calculated and analysed in this study. Other local discomfort parameters - warm/cool floor and radiant asymmetry are not so important in our case. All calculations are made according to equations described in ISO 7730 standard.

TABLE I

CATEGORIES OF THERMAL ENVIRONMENT ACCORDING ISO 7730

\begin{tabular}{|c|c|c|c|c|c|c|}
\hline \multirow{4}{*}{ Category } & \multicolumn{2}{|c|}{$\begin{array}{c}\text { Thermal state of the body as a } \\
\text { whole }\end{array}$} & \multicolumn{4}{|c|}{ Local discomfort } \\
\cline { 2 - 7 } & \multirow{2}{*}{ PPD, $\%$} & PMV & \multirow{2}{*}{$\begin{array}{c}\text { Draught } \\
\text { rate, } \%\end{array}$} & \multicolumn{3}{|c|}{$\begin{array}{c}\text { PD, \% } \\
\text { caused by }\end{array}$} \\
\cline { 5 - 7 } & & & & $\begin{array}{c}\text { vertical air } \\
\text { temperature difference }\end{array}$ & $\begin{array}{c}\text { warm/cool } \\
\text { floor }\end{array}$ & $\begin{array}{c}\text { radiant } \\
\text { asymmetry }\end{array}$ \\
\hline A & $<6$ & $-0.2<$ PMV $<0.2$ & $<10$ & $<3$ & $<10$ & $<5$ \\
\hline B & $<10$ & $-0.5<$ PMV $<0.5$ & $<20$ & $<5$ & $<10$ & $<5$ \\
\hline C & $<15$ & $-0.7<$ PMV $<0.7$ & $<30$ & $<10$ & $<15$ & $<10$ \\
\hline
\end{tabular}

\section{B. Energy efficiency calculations}

The widely used coefficient of performance (or COP) of a heat pump is a ratio of heating/cooling energy provided to electric energy consumed, including energy consumption in all auxiliaries. Declared heat pumps' COP is the value at fixed outdoor temperature $+7^{\circ} \mathrm{C}$, therefore different climate conditions (especially absolute temperature and relative temperature [7]), building characteristics and system settings result in different actual efficiency values during the year. The seasonal coefficient of performance (SCOP) ratio is defined by standard [8] and describes the average annual efficiency. The heating period is divided in hour long periods with different temperatures and COP values are calculated for each period to find the average value.

In this paper the actual energy efficiency ratio (hereinafter AEER) is calculated and analysed for different heating systems installed in the test buildings. As the COP and SCOP ratios are standardized values, but AEER shows the real efficiency for particular set of heat pump system, heat exchangers and settings used, lower ratios are expected. Analysis of electric energy consumption for different heating systems used for the buildings with the same thermal properties allows calculating the AEER for the investigated system under real operation conditions.

Results from the first two years of project running show that three test buildings (CER, LOG and PLY) consume 
approximately the same amount of heating energy. However, the AER and EXP buildings consume slightly more energy mostly because of moisture in constructions $[1,2]$. This fact is taken into account and the energy consumption results are adopted to analyse different heating systems in this paper.

Analysis includes electric energy consumption for heating and for internal sources like data loggers, sensors and other devices that work as internal heat sources. Energy consumption for ventilation can be ignored, because this energy is released by a fan outside. All the consumptions are monitored together with other sensors' data and logged every minute. Example for December 2014 is shown in Fig. 6. Comparative calculations of measured electric energy will be used for analysis of AEER for heating systems from November 2014 to January 2015.

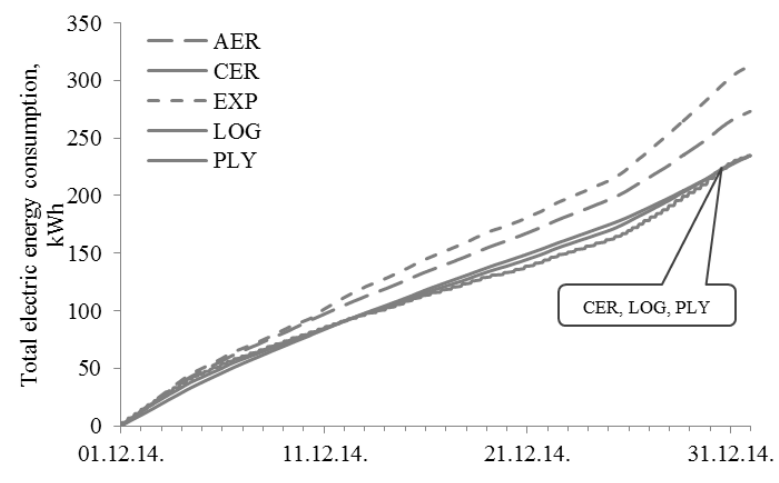

Fig. 6. Total electric energy consumption in December 2014.

\section{RESUlts}

\section{A. Thermal comfort parameters}

The comparison of calculated PPD indices for all test buildings shows that it is very similar in four buildings (AER, CER, EXP and LOG) with totally various heating systems (Fig. 7). It means that all the installed heating systems can provide the same thermal comfort for the similar buildings. The only exception is air-water heat pump with convectors (type A-W.C,) installed in PLY test building. The reason for this is specific temperature regulation regime for this system, which provides a higher temperature difference between switch-on and switch-off. On the other hand, high temperature difference means greater efficiency for this system (see next chapter), because heat pump turns on not so often.

Comparing the PPD indices (Fig. 7) with the defined categories of thermal environment (Table 1), it is seen that at the beginning of measurements the conditions in all the buildings (except PLY) met the B category requirements. However, decreasing of outside temperature at the end of December influences thermal conditions in AER, CER, EXP and LOG buildings to $\mathrm{C}$ category. At this time, the conditions in PLY building did not meet even the requirements of $\mathrm{C}$ category thermal environment.

Comparison of PPD indices for all the installed heating systems depending on the outside and inside temperature is shown in Fig. 8. Graphs clearly show that outside temperature practically does not have an influence on thermal comfort for different heating systems, excluding PLY building due to large temperature amplitude.
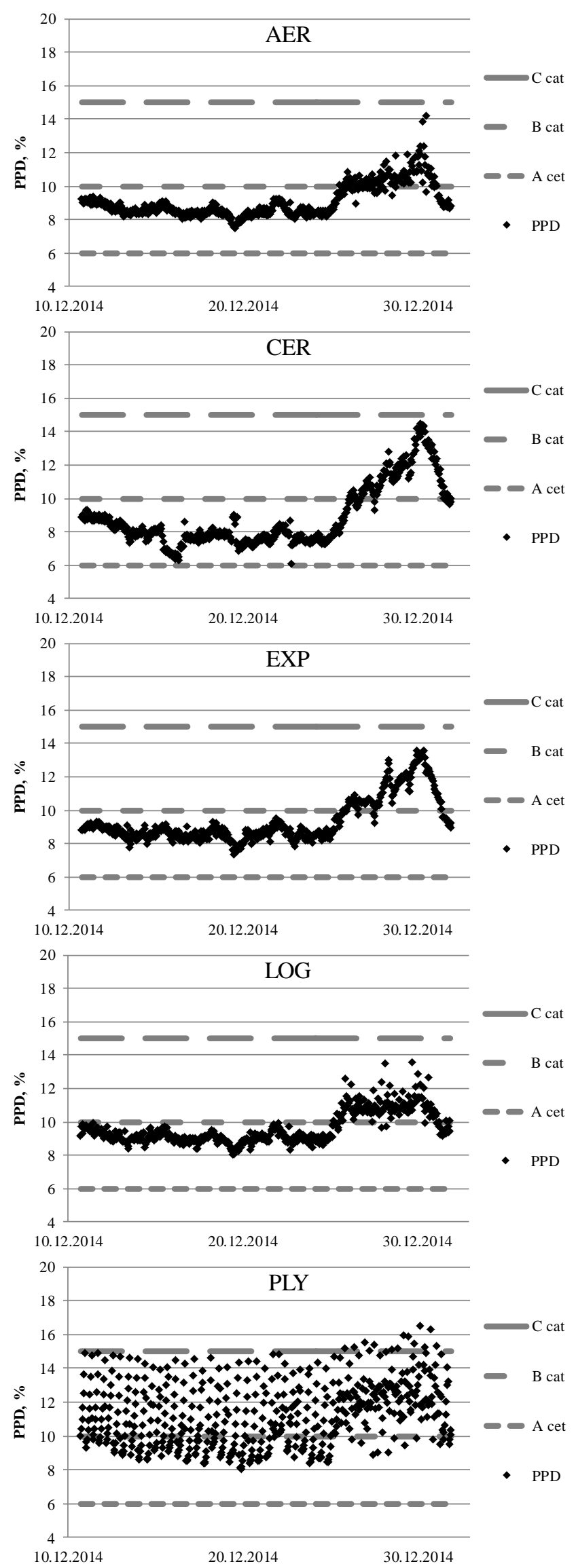

Fig. 7. Calculated PPD indices and their limits for three categories of thermal environment for different heating systems installed in test buildings. 


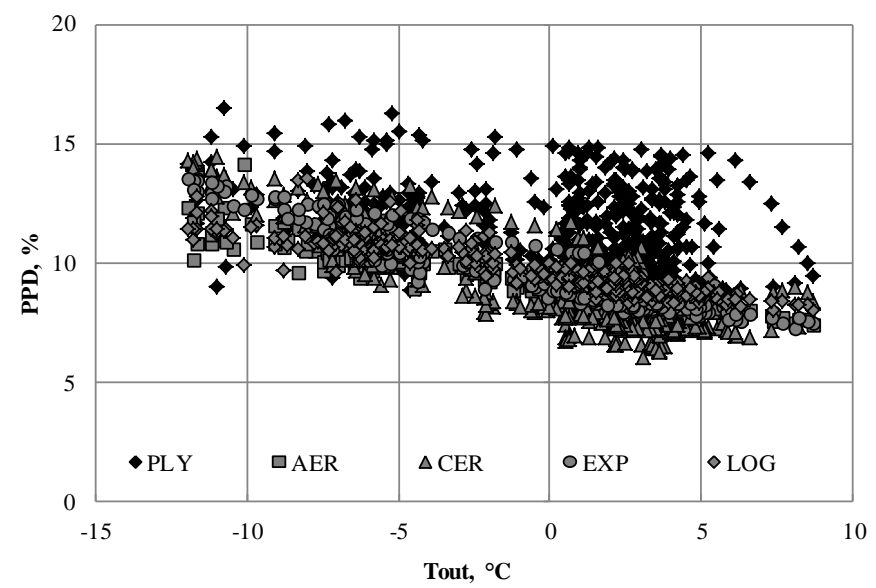

Fig. 8. PPD depending on outside temperatures for different heating systems during the monitoring period.

Analysis of local discomfort in test buildings includes two parameters - discomfort due to draught rate (DR) and due to vertical temperature difference for a sitting person. The first one is calculated using value of $40 \%$ for local turbulence intensity, results are visualized in Fig. 9. As it is seen, practically all the data points are below 6\% level, which corresponds to A category of thermal environment (see Table 1).

Another local discomfort factor PD caused by vertical air temperature difference in the middle of a room is calculated for a sitting person and visualized in Fig. 10. Also in this case, the requirements of A category thermal environment are fulfilled (Table 1), the index does not exceed even 1\%. It should be noted that minimal temperature difference and corresponding PD value are observed in EXP and PLY building with air-water heat pumps, it is the result of low temperature heat carrier (water) and good air homogenization in the rooms except slight hot air layer near the heating capillary mats placed on the ceiling in EXP building.

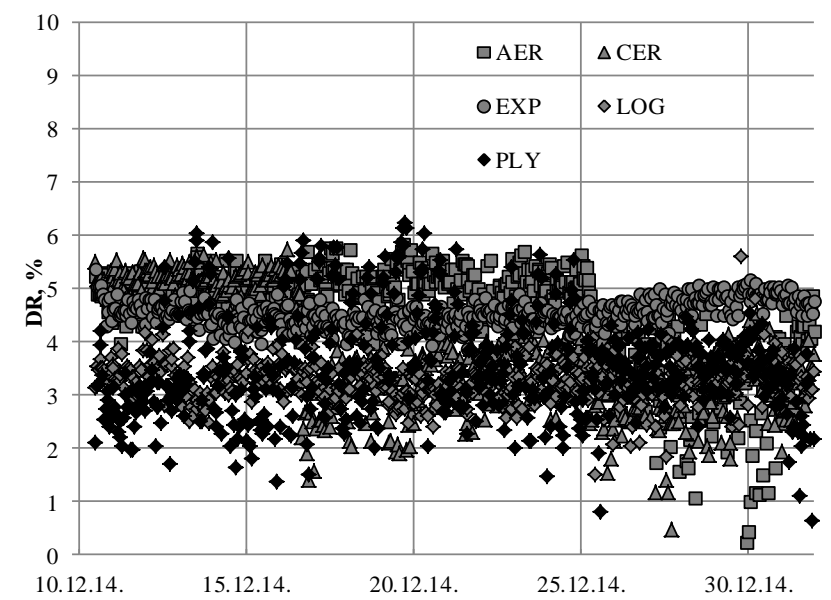

Fig. 9. Local discomfort by draught rate (DR) for different heating systems during the monitoring period.

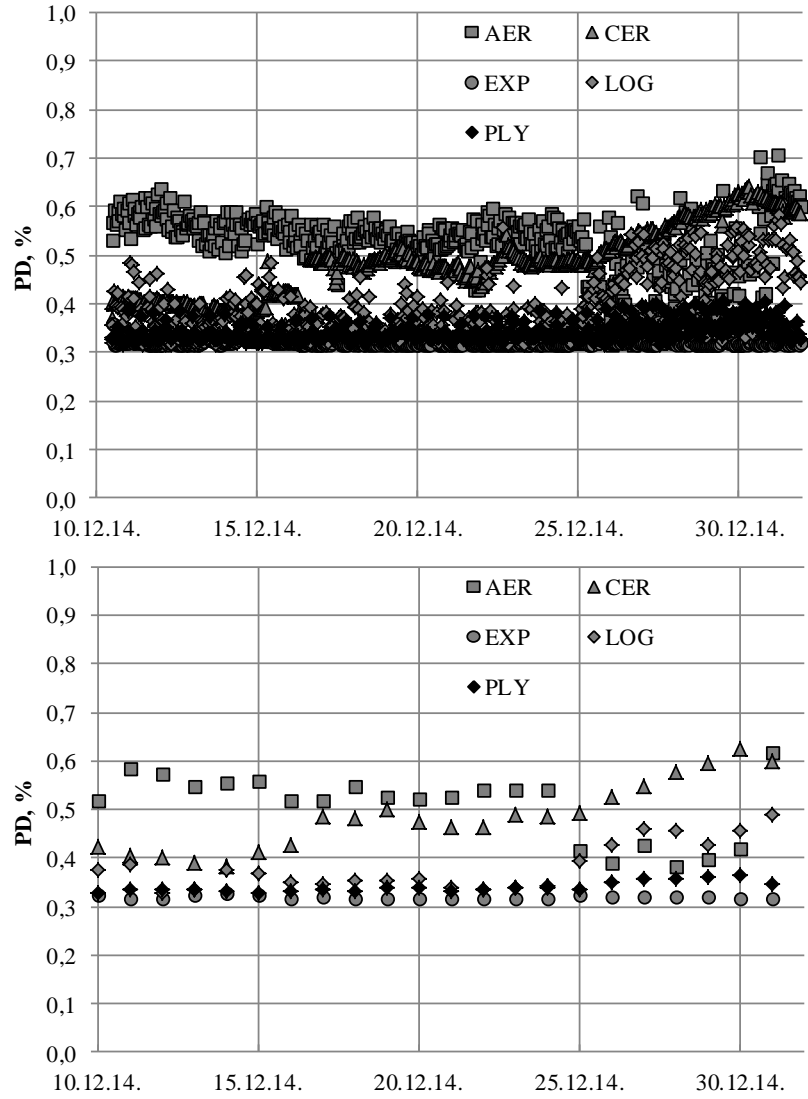

Fig. 10. Local discomfort caused by vertical air temperature difference for different heating systems during the monitoring period. Hourly data is displayed in the picture above and daily averaged data - in the picture below.

\section{B. Energy efficiency calculations}

Calculated AEER values (see Table 2) based on measured electric energy consumption show that air-water heat pump (type A-W.F) in PLY test building works with highest efficiency ratio, but air-water heat pump (type A-W.C) in EXP test house with the lowest one. Such a high ratio for AW.F heating system can be explained mainly by the water temperature settings, which are set in an unusually wide range allowing cooling down of the water by $1.3{ }^{\circ} \mathrm{C}$ (see Fig. 11). At the same time, setting for all other heating systems provides temperature fluctuation typically less than $0.2-0.3{ }^{\circ} \mathrm{C}$. E.g. airair heat pump installed in AER building provides approx. 0.1 ${ }^{\circ} \mathrm{C}$ temperature fluctuations during the first weeks of December 2014 (Fig. 11).

The results obtained for December 2014 and January 2015 when the air temperature outside is below $0^{\circ} \mathrm{C}$ show that heat pump's A-W.C AEER is below 1, meaning that this system was working even below efficiency ratio for electric heater. It can be explained by large proportion of heat losses from heat pump systems outer block. Because of low temperature settings and specific construction -capillary heat exchanger system near the ceiling, heat pump in EXP test building isn't working efficiently in the winter period. Optimization of temperature settings and minimization of heat losses from outer parts of this system can help to improve its efficiency. 
TABLE II

ACTUAL ENERGY EFFICIENCY RATIO (AEER) FOR EACH MONTH AND TEST BUILDING/HEATING SYSTEMS

\begin{tabular}{|c|c|c|c|c|c|c|c|}
\hline Test building & AER & CER & EXP & LOG & PLY & \multirow{2}{*}{ Time period } & $\begin{array}{c}\text { Average outside } \\
\text { temperature }\end{array}$ \\
\hline Heating system & A-A & EL & A-W.C & A-A & A-W.F & & $+3^{\circ} \mathrm{C}$ \\
\hline \multirow{3}{*}{ AEER } & 1.4 & 1.0 & 1.07 & 1.4 & 2.5 & November 2014 & $-0.4^{\circ} \mathrm{C}$ \\
\cline { 2 - 6 } & 1.7 & 1.0 & 0.93 & 1.7 & 2.3 & December 2014 & $-0.2^{\circ} \mathrm{C}$ \\
\cline { 2 - 6 } & 1.7 & 1.0 & 0.94 & 1.7 & 2.5 & January 2015 & \\
\hline
\end{tabular}

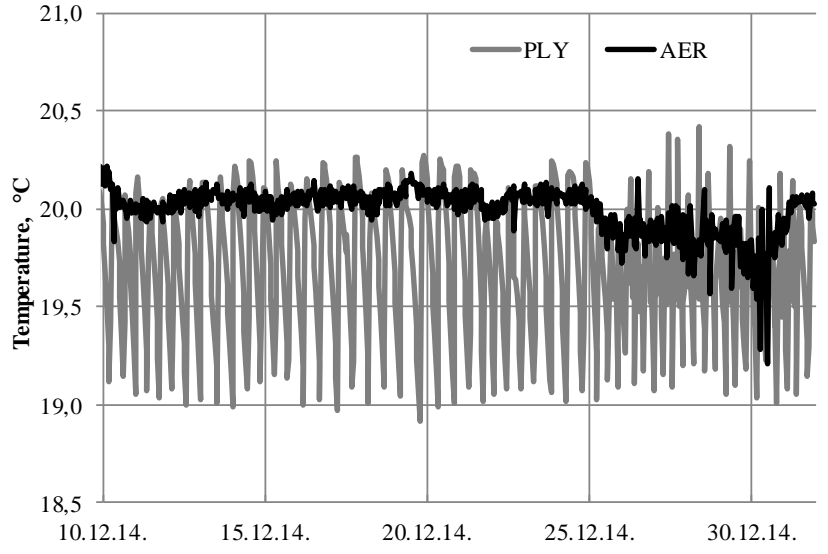

Fig. 11. Long-term monitoring of indoor temperature fluctuation in the middle of the room for heating systems A-W.F (PLY building) and A-A (AER building).

Air-air heat pumps in AER and LOG test buildings work with $\mathrm{AEER}=1.4 \ldots 1.7$ that still are few times lower than defined COP value, which may exceed value of 5 for modern systems [9].

\section{V.DISCUSSION AND CONCLUSIONS}

Long-term monitoring of thermal comfort conditions in the similar test buildings equipped with different heating systems allows analysing the impact of heating system properties and its settings on thermal comfort conditions, which helps to find possible causes of the local discomfort and experimentally estimate the category of the provided thermal environment according to ISO 7730. Our study shows that totally different heating systems with standard settings provide the same level of thermal comfort and it is highly dependent on the environmental parameters (e.g. inside or outside temperature). Lower category of thermal environment is observed in the room when heating system is adjusted to allowing a wide range of heat carrier's temperature, on the other hand, this approach may be used to increase the efficiency of heating system due to less frequent operation. Thus, the balance between thermal comfort and energy efficiency (i.e. running cost) can be adjusted in a necessary direction.

All the heat pumps used in our experiment are over dimensioned for such small test houses with internal volume of $27 \mathrm{~m}^{3}$, but the results are still reliable for comparable qualitative analysis and for future research with different heating systems, their set-ups and settings, as well as types of heat exchangers and heat carriers. Calculated AEER values are several times lower than standardized COP and SCOP values and show a real electric energy usage to provide the heating in particular buildings. In this research, actual energy efficiency of heat pumps depends on heat exchange system properties and settings, that is why the results can only be used for all heating system set analysis and do not represent the type of heating system generally.

\section{ACKNOWLEDGEMENTS}

This research is done with financial support of European Social Fund, project is realized by the University of Latvia, No. 2013/0027/1DP/1.1.1.2.0/13/APIA/VIAA/007.

\section{REFERENCES}

[1] A. Jakovics, S. Gendelis , J. Ratnieks, S. Sakipova. Monitoring and Modelling of Energy Efficiency for Low Energy Testing Houses in Latvian Climate Conditions. International Journal of Energy, 2014 (8): 76-83.

[2] I. Dimdina, A. Jakovičs, S. Gendelis, J. Klaviṇš. Testing of EnergyEfficient Building Envelope Materials in Natural Conditions. World Sustainable Energy Days 2013, European Nearly Zero Energy Buildings Conference, Austria, February 2013.

[3] J. Ratnieks, A. Jakovičs, S. Gendelis. Mathematical modeling of airflow velocity and temperature fields for experimental test houses. Proceedings of the 10th Nordic Symposium on Building Physics, Lund, Sweden,15-19 June 2014, pp. 871-878.

[4] A. Ozolins, A. Jakovics, J. Ratnieks, S. Gendelis. Numerical Modelling of Humidity and Temperature Conditions in Buildings with Different Boundary Structures. Proceedings of the 11th REHVA World Congress \& 8th International Conference on IAQVEC - CLIMA 2013 "Energy efficient, smart and healthy buildings", Prague, Czech Republic, June 16-19, 2013.

[5] S. Gendelis, A. Jakovičs, A. Nitijevskis, J. Ratnieks. Comparison of different air tightness and air exchange rate measurements in very small test buildings. In: 34th AIVC conference: Energy conservation Technologies for mitigation and adaptation in the built environment, Athens, September 2013.

[6] Latvian Standards LVS EN ISO 7730:2005 - Ergonomics of the thermal environment - Analytical determination and interpretation of thermal comfort using calculation of the PMV and PPD indices and local thermal comfort criteria, 2005.

[7] I. S. Ertesvåg, Uncertainties in heat-pump coefficient of performance (COP) and exergy efficiency based on standardized testing, Energy and Buildings, Volume 43, Issue 8, August 2011, 1937-1946. http://dx.doi.org/10.1016/j.enbuild.2011.03.039

[8] European Committee for Standardization (CEN), EN 14825 - Air conditioners, liquid chilling packages and heat pumps, with electrically driven compressors, for space heating and cooling - Testing and rating at part load conditions and calculation of seasonal performance, 2012.

[9] X. Liu, L. Ni, S.-K. Lau, and H. Li, Performance analysis of a multifunctional Heat pump system in heating mode, Applied Thermal Engineering, Volume 51, Issues 1-2, March 2013, Pages 698-710. http://dx.doi.org/10.1016/j.applthermaleng.2012.08.043 